\title{
LOS LIBROS DE EMBLEMAS Y LA IMPRENTA
}

\author{
SAGRARIO LÓPEZ POZA
}

Universidade da Coruña

ـ que libros de emblemas difundieron una cultura simbólica codificada humanistas, moralistas, sacerdotes, políticos y artistas plásticos. Las especiales características de este tipo de obras, con abundantes grabados, requería una infraestructura industrial de la que no todas las casas impresoras de los siglos XVI y XVII disponían, y sólo unas cuantas más destacadas se especializaron en su producción. Ello impidió a veces que libros que habían sido concebidos para llevar grabadas las correspondientes picturae se produjeran acompañados de los grabados correspondientes. En algunos países de Europa, especialmente en aquellos con una tradición de talleres de burilistas y grabadores y de imprentas especializadas, hubo centros impresores que destacaron por la producción de libros con presencia de las diversas variedades del género emblemático (empresas, emblemas, divisas, jeroglíficos, grabados de decoraciones festivas).

Por otra parte, los mismos impresores, en muchas ocasiones poseedores de una notable cultura humanística, se hicieron eco de la moda de la emblemática en sus propias divisas o empresas, que denominamos marcas de impresor. 
También los emblemas formaron parte de portadas de libro alegóricas grabadas, pasquines y otro tipo de materiales (producidos en la imprenta o en talleres vinculados a ella) que contribuyeron a fijar lo que en muchas ocasiones no fue más que un arte efímero.

De estos aspectos pretendo tratar aquí1.

El empleo de grabados (xilográficos o calcográficos) unidos a la palabra hizo de los libros de emblemas un material didáctico de primer orden. La filosofía moral, la ética civil, las convenciones morales, políticas o religiosas encontraban en los emblemas y empresas unos aliados perfectos para llamar la atención apelando a los ojos primero y luego, una vez comprendido el mensaje, ayudando a grabar el concepto expresado en la memoria por medio de la imagen. Pero el empleo de ilustraciones grabadas dificultaba en gran medida la producción de este tipo de obras, porque requería un complicado proceso en el que se veían involucrados el emblemista, el artista que dibujara los conceptos que el autor deseaba plasmar, el grabador que abriera las planchas, el editor o librero que pagara la edición y el impresor.

La producción y éxito de los libros de emblemas están intrínsecamente unidos al desarrollo de la imprenta como fenómeno comercial. Los impresores vieron que ese producto podía suponer para ellos considerables beneficios, a pesar de que el empleo de ilustraciones grabadas dificultaba en gran medida la producción de este tipo de obras. Las ilustraciones xilográficas siempre resultaban más baratas, pues podían imprimirse junto con el texto, ya que la presión que requerían era similar a la de la prensa tipográfica. Los tacos de madera con la ilustración solían sufrir un desgaste importante con el uso repetido, pero podían retallarse y aprovecharse de nuevo si la tirada era larga, o para otra edición. Las maderas empleadas para los tacos solían ser de cerezo, manzano y, sobre todo, peral, maderas asequibles todas ellas. Pero los grabados calcográficos, además de una plancha metálica, requerían un doble paso por la prensa (la tipográfica -para el texto- y el tórculo -para las ilustraciones-) y ello requería muchísimo más tiempo y pericia, lo que encarecía considerablemente la edición.

Aun así, la producción de libros de emblemas, si bien requería una importante inversión previa para la elaboración de los grabados, solía compensar al editor con una venta de la totalidad de la tirada.

\footnotetext{
1 Acompañar este trabajo de una bibliografía de todos los libros de emblemas citados excedería fuera de los razonable el espacio de que dispongo. Remito a los repertorios bien conocidos de Praz, Landwehr, Campa y otros cuya referencia completa puede hallarse en la sección de bibliografía (Repertorios bibliográficos) de la página web: <http:/ / rosalia.dc.fi.udc.es/emblematica>.
} 
Algunos países tenían una larga tradición de talleres de artistas grabadores, como la zona de Flandes y Holanda, pero en otros, como España (cuya imprenta pasaba por momentos difíciles), era manifiesta la escasez de expertos grabadores en cualquier modalidad, lo que dificultaba enormemente la producción de libros de emblemas y obligaba a los emblemistas a acudir a artesanos extranjeros, o incluso a publicar sin imágenes libros que habían sido concebidos para llevar ilustraciones. De ello se queja Sebastián de Covarrubias en el prólogo de sus Emblemas morales en que confiesa que encontró artistas que dibujaran la figura del emblema, pero que no halló quien tallara los tacos xilográficos. Hubo de ser más tarde cuando encomendara la labor a oficiales extranjeros. El proceso de redacción y preparación de su obra pudo durar, pues, unos quince años hasta que se vio impresa en Madrid, en 1610, por Luis Sánchez (figura 1).

Es fácil, pues, comprender que como pocas imprentas y editores disponían de los medios materiales y los recursos humanos que precisaba la elaboración de libros de emblemas, cuando una casa editorial mostraba su pericia en estos menesteres, a ella acudían los autores o los promotores de la obra en busca de su experiencia.

Las ciudades que más libros de emblemas produjeron en sus

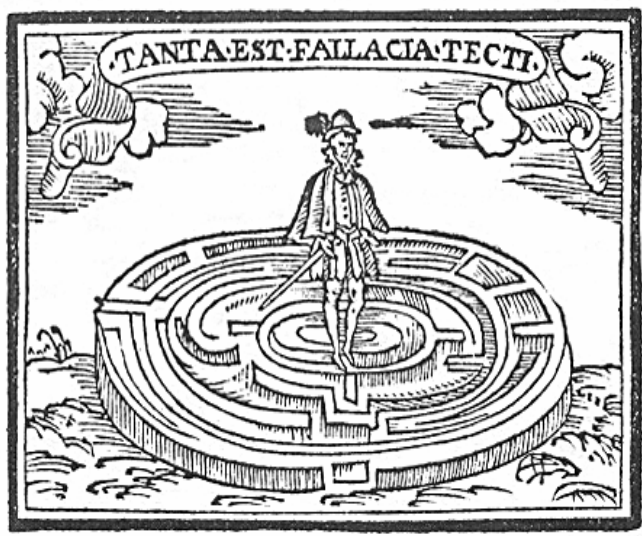

[Figura 1] imprentas fueron París y Lyon (de cuyas prensas salieron los mejores de Europa durante los siglos XVI y XVII). En esa ciudad francesa, en el siglo XVI, destacó el impresor que parece haber producido mayor número de estos libros de toda Europa: Guillaume Rouillé, a quien se deben no menos de veinte ediciones de los emblemas de Alciato, desde 1548 hasta 1580, con continuación hasta 1616 por sus herederos. En la misma ciudad ejercieron Anisson \& Posuel, que editaron obras españolas, como la Idea de el buen pastor, más conocida como las Empresas sacras de Núñez de Cepeda.

Entre las imprentas que destacaron en los Países Bajos en la producción de libros de emblemas está la de Cristóbal Plantin en Amberes, (aunque también los imprimió en su oficina tipográfica de Leiden). Su casa editorial se ocupó de la impresión, entre 1561 y 1590, de unas cincuenta ediciones. Como buen hombre de negocios, Plantin fue sensible a la demanda de libros de emblemas y a las ganancias que podían proporcionar. En 1561 apareció la 
primera obra de este tipo en su taller, a la que seguirían otra larga serie. Se trata de Devises Herö̈ques, de Claude Paradin, que había sido editada diez años antes en Lyon, por Jean de Tournes y Guillaume Gazeau. En 1564 publicó los Emblemata del húngaro Szambot (Johannes Sambucus). Los emblemas de Sambucus aparecieron primero en latín, con 166 picturae xilográficas de Cornelio Muller, Arnaldo Nicolai y Gerardo Jansen van Kampen, sobre dibujos de Lucas d'Heere y Pedro Huys. La siguiente edición, de 1567, añadía 55 picturae con diseño de Pedro van der Borcht (figura 2).

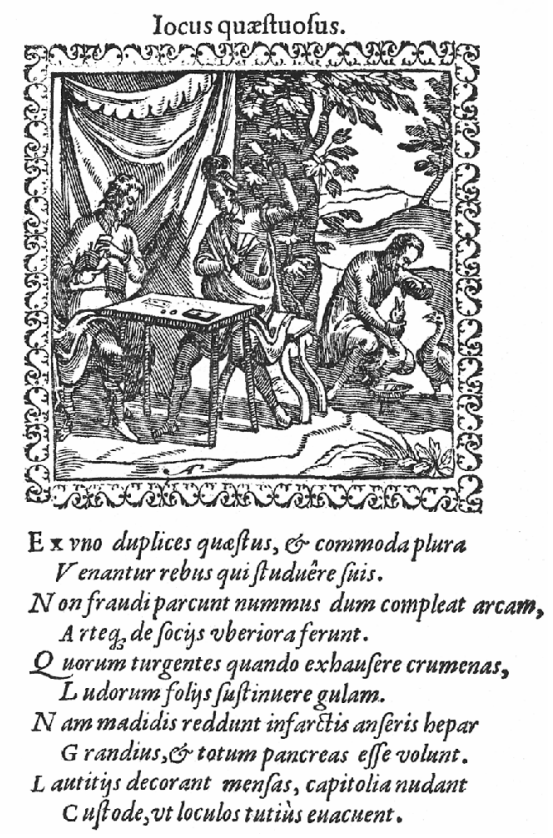

Figura 2

Plantin realizó diez ediciones de los emblemas de Alciato, y sus sucesores otras tantas. De ellas, la más fina es la realizada en octavo que apareció en 1577. Los herederos de Plantin siguieron ocupándose de libros de emblemas o materias relacionadas con ellos. Fue especialmente fecunda la etapa en que colaboraron con su taller eminentes artistas, como Pedro Pablo Rubens, que dibujó un importante número de portadas alegóricas, la marca de impresor de la oficina plantiniana y varios libros de carácter emblemático y festivo. 
En Bruselas fue notable la producción de François Foppens, que destacó por sus ediciones de las Empresas morales de Juan de Borja, en su edición completa (1680) y uno de los libros más hermosos de emblemas, los Emblemata Horatiana de Otto van Veen (Vaenius), maestro de Pedro Pablo Rubens, cuya versión española debemos a este impresor con un nuevo título: Theatro moral de la vida humana: en cien emblemas (1672).

En Italia, destacó Venecia, con cuarenta y cinco impresores que se ocuparon de libros de emblemas a lo largo de los siglos XVI y XVII. Sobresalen entre ellos, por número de ediciones, Francesco de Franceschi, que se ocupó de editar las Imprese illustri de Ruscelli, Delle imprese de Bargagli y los Commentaria symbolica de Ricciardi. También Nicolo Pezzana destacó por sus ediciones de la Iconología de Ripa y la versión italiana de las Empresas políticas de Saavedra Fajardo, de la que hizo dos ediciones (1677 y 1684) así como varias obras de Labia: Dell'imprese pastorali, Simboli predicabili, Simboli festivi, Horto simbolico.

En España, a pesar de la situación delicada de la imprenta, sobre todo a partir de la segunda mitad del siglo XVI, también hubo producción de libros de emblemas. Destaca Madrid, donde unos veinte establecimientos se ocuparon de libros de emblemas en los siglos XVII y XVIII. A finales del siglo XVI (en 1599) los talleres madrileños de los herederos de Juan Iñíguez de Lequerica habían producido las Emblemas moralizadas de Hernando de Soto. En 1610 se imprimió en Madrid una de las principales obras emblemáticas españolas, los Emblemas morales de Sebastián de Covarrubias, en la imprenta de Luis Sánchez. La otra ciudad que destaca más en estos menesteres es Valencia, que vio varias ediciones de las empresas de Saavedra Fajardo y de las de Núñez de Cepeda, así como de la Declaración de los emblemas de Alciato de Diego López. Cabrera y Villagrasa fueron los editores de mayor producción.

En Nájera, en 1615, se imprimió la primera edición de la Declaración magistral de los emblemas de Alciato por Diego López en la imprenta de Juan de Mongaston, que reproducía toscamente las estampas de la edición de Lyon de 1549 de los emblemas de Alciato, copiándolas invertidas e introduciendo cambios no exentos de errores. Sevilla vio la obra de Ortiz Memoria, entendimiento y voluntad en 1677, de los talleres de Juan Francisco de Blas.

Valladolid produjo una obra que destaca por el grabado calcográfico: el pequeño libro titulado Affectos divinos con emblemas sagrados, de Herman Hugo, que fue traducido por Pedro de Salas y editado por Gregorio de Bedoya en 1658. Entre sus 45 emblemas anónimos, hay uno con dibujo de Francisco Rizi. En Burgos se editó la obra de Nicolás de la Iglesia Flores de miraflores por parte de Diego de Nieva y Murillo. 
Entre los grabadores que abrieron planchas en España para libros de emblemas, destacan Roberto Cordier, que trabajó para la primera edición de los Emblemata Regio Politica de Juan de Solórzano Pereira (Madrid, García Morrás, 1653); Juan Felipe Jansen y Marcos Orozco y Diego de Obregón que grabaron las láminas de la obra de Juan de Baños de Velasco L. A. Seneca Ilustrado en blasones políticos (Madrid, Mateo de Espinosa y Arteaga, 1670), en que firma el mismo Obregón como inventor de las cuatro que graba.

Hubo países en que la floración fue temprana, como en Francia, en que el apogeo de la producción fue entre 1534 y 1570, pero en España, aunque se conoció muy pronto a Alciato (Antonio Agustín cita su obra en 1538), no se imprimió un libro de emblemas hasta 1589 (Juan de Horozco, Emblemas morales). Unos años antes (1581) en Praga, otro español, Juan de Borja, había editado sus Empresas morales. Nuestra imprenta pasaba grandes dificultades a finales del siglo XVI, pero aun así, los emblemistas españoles produjeron más de una treintena de obras ilustradas, algunas de las cuales gozaron de varias reediciones. En total se crearon más de 2.000 picturae, a pesar de las circunstancias. Muchas otras obras se imprimieron sin la imagen por las razones apuntadas.

\section{Las marcas de impresor}

Las marcas de impresor o marcas tipográficas utilizaron también en la etapa de la imprenta manual las convenciones emblemáticas. Habían comenzado siendo apenas unas siglas o un anagrama del nombre del impresor, pero a medida que la cultura simbólica y el gusto por la analogía fue tan apreciada, los impresores y editores adoptaron la costumbre de emplear como marca de identificación una empresa o una divisa que intentara transmitir un concepto considerado por quien la elegía como lema de su vida y su producción. A menudo varios impresores usaban si no la misma marca que otro, una muy parecida; en Francia, Francisco I promulgó en 1539 normas por las que se prohibía a los impreseroes utilizar marcas tipográficas que pudieran confundirse con las de otro.

Las divisas de impresor o marcas tipográficas, con frecuencia, aunque no siempre vayan acompañadas de lema, evocan un emblema o material emblemático bien conocido por los humanistas. De hecho, la mayor parte de las marcas tipográficas no difieren en absoluto de lo que se consideraba una empresa, y como ellas, suelen cumplir los requerimientos preceptivos marcados por los tratadistas. Los motes, a veces procedentes de versos latinos, suelen ser agudos, equívocos, breves y en latín y las picturae presentan las cualidades de 
Los libros de emblemas y la imprenta

simetría, proporción y demás requisitos expresados como deseables en los prólogos de los libros de empresas y en tratados de Retórica².

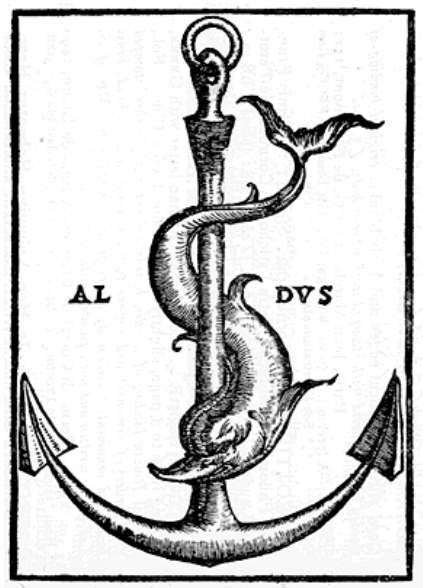

Figura 3

Sírvanos como ejemplo la marca tipográfica más famosa de la historia de la imprenta: la del impresor de Venecia Aldo Manucio (un delfín enroscado en la caña de un ancla -figura 3-), que utilizó no sólo Aldo, sino sus descendientes (él murió en 1515) y varios editores posteriores hasta el siglo XX, como William Pickering, de Londres (siglo XIX), o la Colección Áncora y Delfín de la editorial española del siglo XX. El viejo Aldo la empleó por primera vez en la obra Poetae christiani veteres (Venecia, 1502). El áncora y el delfín aparecían en monedas romanas de la época imperial en tiempos de Tito y Domiciano. Es bien conocida una moneda de Tito Vespasiano con el motivo (80 D. C.), que sabemos que poseía el impresor de Venecia (figura 4)3 Manucio se decidiera a tomarla como la marca tipográfica de su imprenta influido por un pasaje de la Hypnerotomachia Poliphili de cuya editio princeps se ocupó él mismo(Venecia, 1499). Esta obra se convertiría en uno de los más célebres libros ilustrados de la historia de la imprenta. Las xilografías que adornan la obra fueron talladas por un artista anónimo, aunque algunos lo identifican con el veneciano Benedetto Bordon. En el capítulo VII, cuando Polyphilo sale del terrible laberinto de lo que podría llamarse «amor animal» y va a penetrar en la región de los Cinco Sentidos y del Libre Albedrío, halla un paraje ameno en que ve un antiquísimo puente que tiene en sus pretiles unos

2 Para abundar en estos aspectos, ver la Introducción a mi edición de las Empresas Políticas de Saavedra Fajardo, Madrid, Cátedra, 1999.

3 Ver Antonio Agustín, Diálogos de Medallas, inscripciones y otras antigüedades, Tarragona, Felipe Mey, 1587, diálogo II. 
jeroglíficos que describe minuciosamente. Entre ellos, un círculo y un ancla, sobre cuya caña se enroscaba un delfín. Poliphilo interpreta el mensaje en griego y da su traducción: «semper festina tarde» (apresúrate siempre despacio), que viene a recomendar la paciencia y la acción realizada oportunamente (figura 5). Colona está aplicando las convenciones simbólicas al uso inspiradas por los Hieroglyphica de Horapolo, y así el círculo significaría «semper», el delfín «festina» y el ancla «tarde». Poco antes de que el tema apareciera en El sueño de Polifilo, el jeroglífico del áncora asociada al delfín y el mote Semper festina lente aparecieron mencionados en una carta de Aldo Manuzio a Alberto Pio da Carpi (14 de octubre de 1499).

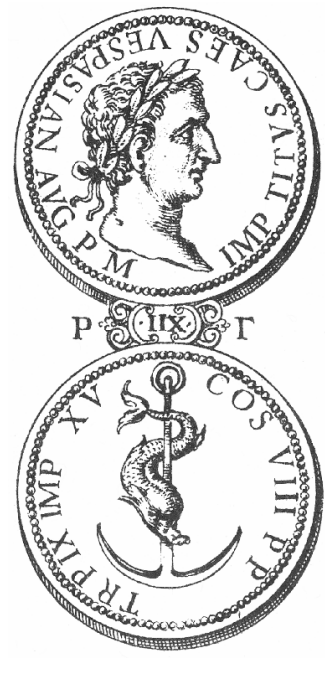

Figura 4

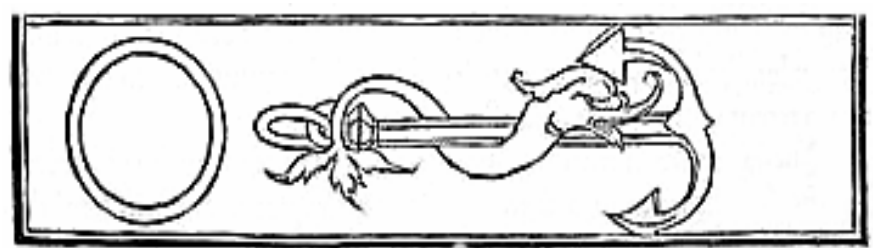

Figura 5

También pudo estar influido por Erasmo, que como es sabido fue huésped de Aldo, y que dedica a este lema extenso comentario en sus Adagia. La primera versión de esta obra es de 1500, y Aldo Manucio publicó los Adagia de Erasmo en 1508. En el adagio 2.1.1., al glosar el lema Festina lente («apresúrate despacio»), Erasmo comenta cómo Aldo le mostró una moneda antigua de Vespasiano; dice que el lema es digno de ser grabado en todas las columnas y escrito con letras de oro en las puertas de los templos, y explica que por eso está pintado en las salas de los magnates y lo llevan los caballeros en sus anillos y los reyes en su cetro. La misma divisa imperial de Tito es comentada por Gabriele Simeoni en sus Imprese heroiche et morali ${ }^{4}$ que afirma que el emperador Augusto usó el mote con la imagen de un cangrejo y una mariposa, expresando de ese modo «la templanza e modestia del suo animo» (figura 6).

\footnotetext{
4 Gabriele Sieoni, Le Imprese heroiche et morali ritrouate da M. Gabriello Symeoni fiorentino ..., Lyone, appresso Guglielmo Rovillio, 1559.
} 


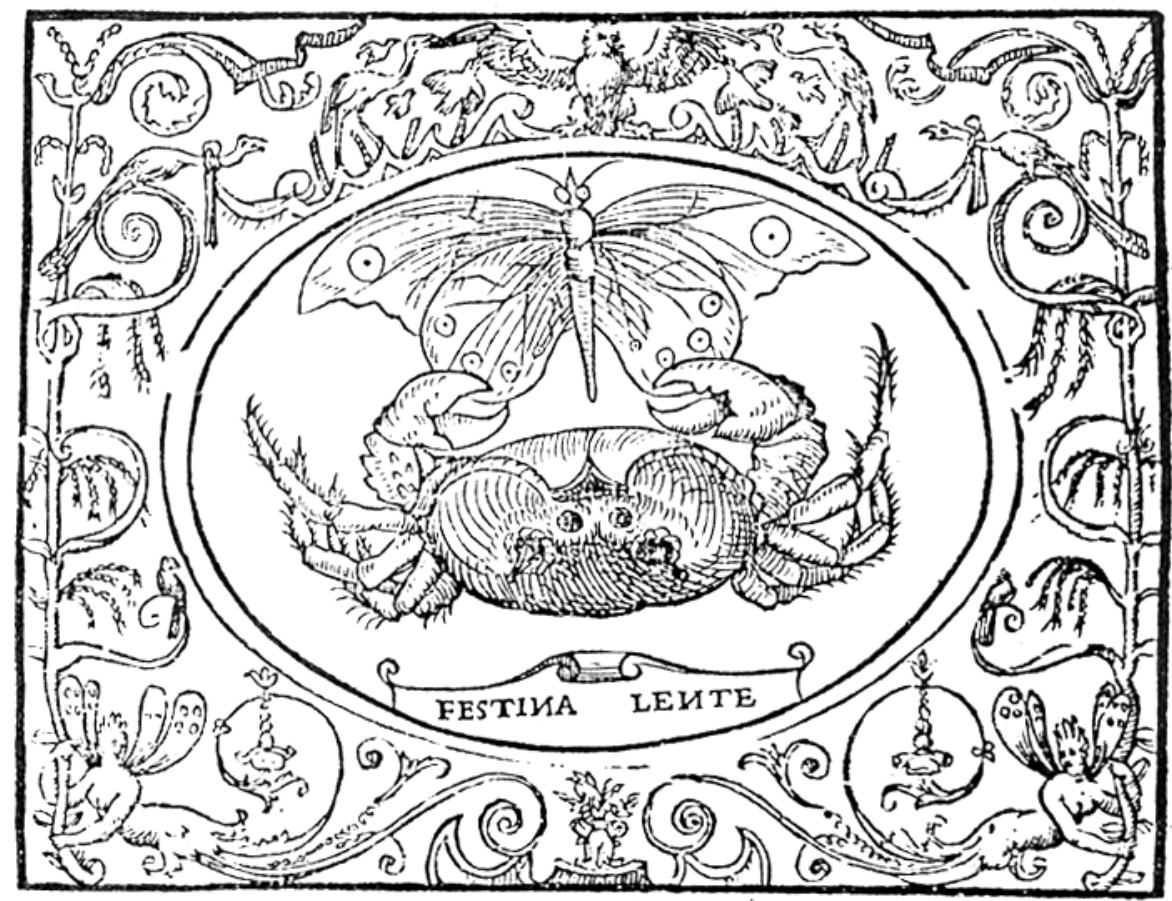

Figura 6

Como material emblemático que es, se puede ver una trayectoria por un lado de la pictura y por otro del lema. Andrea Alciato emplea la imagen del áncora y el delfín en su emblema CXLIII: Princeps subditorom incolvmitatem procvrans («Del príncipe que procura la seguridad de sus súbditos»), y Geoffrey Whitney emplea la imagen del cangrejo y la mariposa, con el lema Festina lente en el número 121 de su A Choice of Emblems and other Devices (1586). El mismo lema se asoció con distintas imágenes, siempre para significar los dos conceptos opuestos de «sin prisa pero sin pausa»; se emplearon, entre otros, los siguientes motivos: un caracol, un hombre tirando de la cola de un caballo, una mano vertiendo agua con una jarra (marca de Bartholomaeus Honoratus - figura 7-), una tortuga alada (o movida por la vela de un barco - como la marca del impresor Bartolomeo Sermartelli (figura 8) -... 


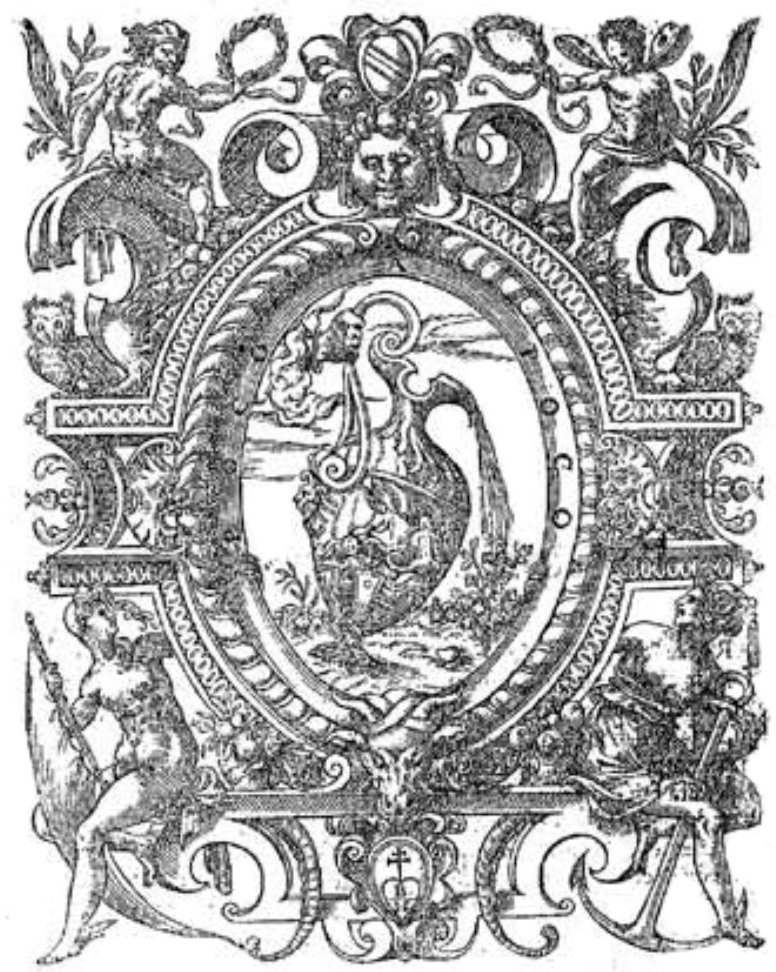

Figura 7

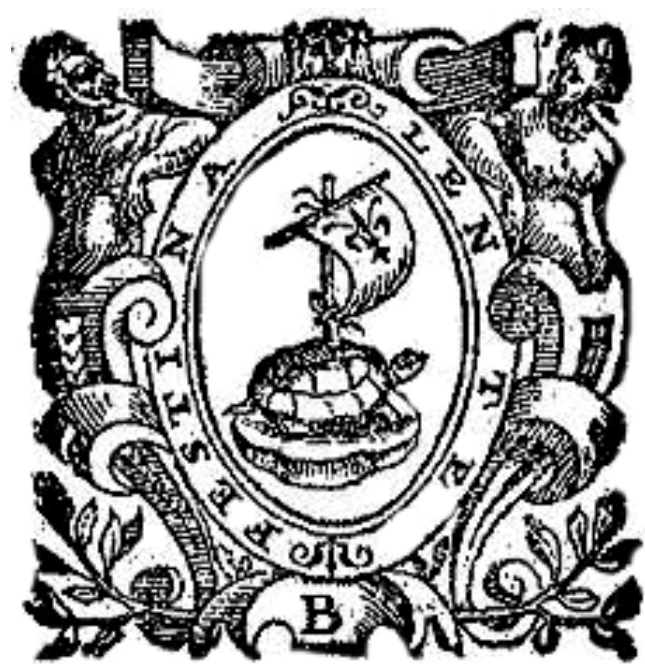

Figura 8

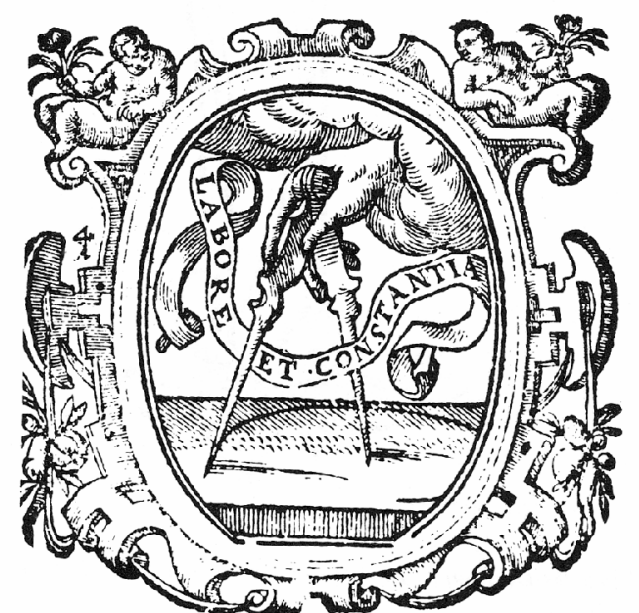

Figura 9

LECTURA Y SIGNO, 1 (2006) pp. 177-199 
Otra de las marcas de impresor más conocidas es la de Cristóbal Plantin, que aunque empleó variantes, nunca faltaron en los diversos diseños dos elementos: el lema «Labore et constantia» y una mano que traza con un compás un círculo. La aguja del compás que está moviéndose representa el trabajo, la que está quieta, la constancia, y el propio círculo evoca la eternidad (jeroglífico de Horapolo), de modo que la leyenda transmite el concepto de que con trabajo y constancia se consiguen obras que trascienden el tiempo (figura 9).

Significativa fue la empresa de Gabriele Giolito y sus hermanos (Venecia, entre el 1536 y 1591), que tantos libros produjo en relación con España por su colaboración con Alonso de Ulloa - figura 10- y que nos muestra una fenix dirigiéndose al sol, de donde resurgirá de nuevo tras convertirse en ceniza. Como indica la filacteria, él permanecerá siempre el mismo - con la constancia estoica - a pesar de los avatares de la fortuna cambiante y caprichosa (representada por la bola alada que sostiene al ave).

La bellísima marca del impresor Marcolini (figura 11) lleva por lema: Veritas filia Tempus, y eso es lo que se representa en la pictura: al Tiempo, con sus atributos (alas y reloj de arena), que libera a la Verdad (joven desnuda), del Fraude o el Engaño (representado con pies y cola de animal, y con unas serpientes en la mano). Tarde o temprano, el tiempo revela la verdad a pesar del engaño.

No podemos seguir y habrán de bastar como ejemplo estas pocas muestras 5 .

\section{Portadas de libros y grabados emblemáticos}

Las portadas de los libros del Siglo de Oro transmiten un mensaje que debe ser leído considerando los códigos en que fueron ideadas. A menudo sus diseñadores se inspiran en los arcos de triunfo romanos, que servían para los actos solemnes de entradas de los generales victoriosos, en un deliberado intento de ensalzar a personajes poderosos. Las portadas preparan al

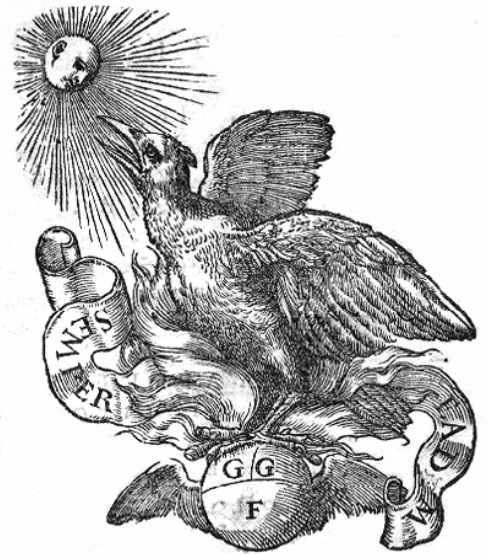

Figura 10

\footnotetext{
${ }_{5}$ Para marcas de impresores italianas, ver G. Zapella, Le marche dei tipografi e degli editori italiani del Cinquecento, 2 v., Milano, Bibliografica, 1986. Sobre marcas de impresores flamencos, la magna obra: P. van Huisstede \& J.P.J. Brandhorst, Dutch Printer's Ddevices 15yh-17th century. A Catalogue, Nieuwkoop, De Graaf Publishers, 1999. 3 vols. y un CD-ROM.
} 
lector para acceder a lo que contiene el libro y le transmiten mensajes icónicos plagados de artificios de agudeza para poner a prueba la pericia y competencia de los lectores. Es un asunto interesante y tan amplio, que ahora no podemos tratar con la dedicación que merece, y sólo apuntaremos unas líneas generales.

El incremento en este tipo de portadas está ligado a Rubens, su colaboración con el taller de imprenta de Plantin-Moretus y sus diseños para entradas solemnes de personajes relevantes en los Países Bajos (de los que luego se hacían estampas que se divulgaban sueltas o en forma de libro). Su más temprana portada con este tipo de decoración data de 1613, para el Opticorum Libri Sex de Aguilon, y a él se debe la hermosa portada de las obras completas de Justo Lipsio de 1637 (figura 12), grabada por Cornelis Galle y que estaba ya acabada en 1634 (la publicación hubo de retrasarse por falta de papel).

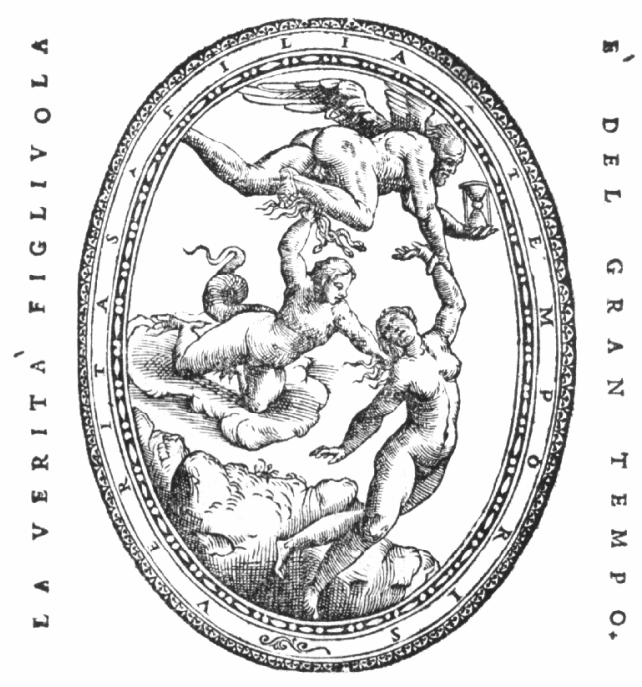

Figura 11 


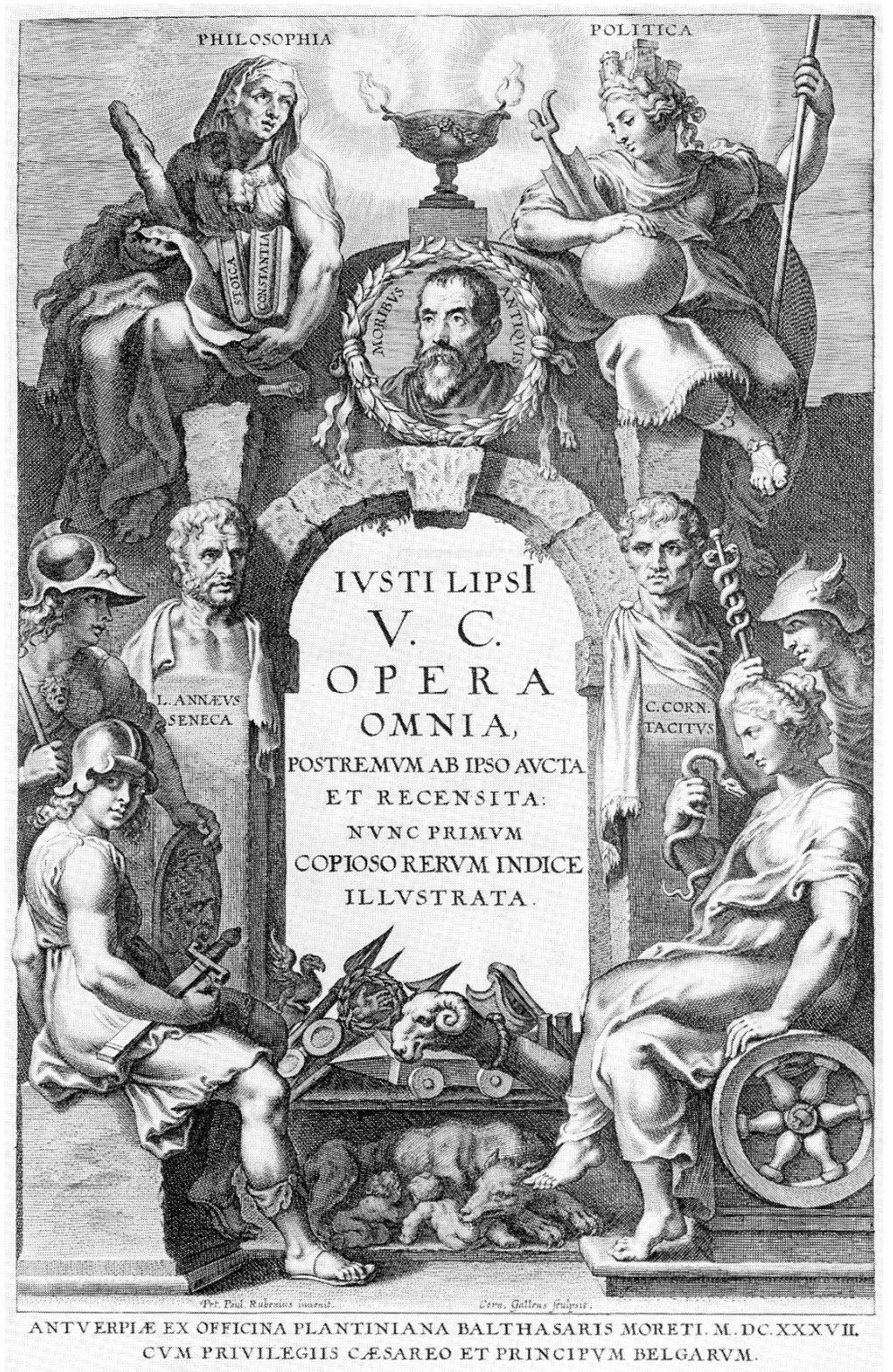

Figura 12

El dibujo de Rubens presenta, como muchas de las portadas calcográficas de entonces, un arco triunfal. Los arcos se asociaban con el triunfo (Rubens había estudiado con detalle, en un viaje juvenil a Roma, los tres arcos que habían permanecido en pie del antiguo imperio: los de Tito, Septimio y Constantino, que ostentaban sus victorias militares. Para un escritor de fama, sus obras equivaldrían a esas victorias en el terreno intelectual. 
En esta portada se registra la excelencia de Lipsio para que perdure en la posteridad. En la antigua Roma estos objetivos se lograron por medio de recursos visuales, estatuas, relieves e inscripciones. En la portada, el retrato de Lipsio y el título del libro realizan la función de la inscripción romana. El arco separa el mundo de los que lo ven de la esfera de los trabajos de Lipsio, y las figuras de Tácito y Séneca (a cuya obra dedicó sus máximos esfuerzos el humanista belga) invitan al lector a entrar. Figuras alegóricas celebran los logros de Lipsio y una lámpara funeraria sobre su retrato mantiene su memoria viva con una llama. El retrato de Lipsio, encima de la clave del arco, está rodeado de una corona de laurel, y dentro aparece el lema de Lipsio "moribus antiquis". La corona de laurel era el premio de la victoria en los juegos pitios en honor de Apolo y era llevada por el triumphator romano. Flanqueando el retrato, figuras alegóricas de la Filosofía y la Política. Cada una sentada en una base de columna que está sobre la cabeza del principal autor clásico que inspiró a Lipsio: Séneca para la Filosofía y Tácito* para la política. La Filosofía es una mujer vieja con los atributos de Hércules: la piel de león y la porra. Su edad y su expresión muestran la sabiduría de la experiencia, mientras que los atributos de Hércules la asocian con el héroe estoico, que trabajó por el bien de la humanidad y eligió la virtud y el trabajo frente a la comodidad. Ella mantiene en sus manos dos libros que dicen Stoica y Constantia; el primero parece un plural adjetivo neutro "escritos estoicos" y debe referirse a las obras de Lipsio Manuductio y Physiologia Stoicorum, mientras que el último se refiere al primero y más importante trabajo sobre el estoicismo: De constantia. Séneca está debajo de la Filosofía, como la fuente clásica para la interpretación del estoicismo. Al lado de Séneca, Minerva, diosa de la sabiduría, armada. Ella protegía la antigua ciudad de Atenas y compartía con Juno el templo de Júpiter en el monte capitolino de Roma. A la derecha está la personificación de la política, situada sobre Tácito, y se refiere sobre todo a la Politica de Lipsio, sustentada en Tácito. Lleva un timón, símbolo del buen gobierno y una lanza, símbolo de la autoridad militar, mientras que en su rodilla equilibra la esfera que simboliza el poder mundial. Sobre su cabeza, la corona de torre de Cibeles, que evoca el poder cívico y el orden. Bajo ella, el Término de Tácito, al lado del cual está Mercurio, garante de la paz y el que inspira una oratoria persuasiva esencial para el gobernante de un estado bien ordenado.

Al pie de cada lado del arco están las figuras de la virtud (izquierda) con espada y casco. Frente a ella, a la derecha se sienta una mujer de dos caras que lleva en su mano derecha una serpiente y su izquierda reposa en una rueda, símbolo del buen gobierno. Esta figura es la Prudencia, el atributo por excelencia del buen príncipe y asociada por Lipsio a Tácito. Bajo el centro del

${ }^{*}$ (Lipsius 1589) 
Los libros de emblemas y la imprenta

arco, atributos militares romanos: el águila, las lanzas, el estandarte legionario y los carneros batientes o arietes. Aquí representan las obras de Lipsio sobre técnicas militares romanas: el De militia romana y el Poliorceticon. Bajo este grupo están Rómulo y Remo siendo amamantados por la loba6.

No hay detalle, como puede verse, que no haya sido minuciosamente pensado; nada es ocioso, y todo conduce a la exaltación del autor, Justo Lipsio, y de su obra, a la que se invita a entrar a través de la portada.

Para un juego semejante de compleja información transmitida sobre una portada, puede servir de ejemplo las dos que se emplearon en la obra de Saavedra Fajardo Idea de un príncipe político-christiano representada en cien empresas con variantes entre la primera versión (1640) y la segunda (1642). He dedicado a ellas un trabajo detallado al que remito para no extenderme aquí ${ }^{7}$.

\footnotetext{
6 Para otros trabajos de Rubens semejantes, ver Mark Morford, Stoics and Neostoics. Rubens and the Circle of Lipsius, Princeton, Princeton University Press, 1991.

7 «Variantes en las portadas y en las picturae de las dos versiones de las Empresas políticas de Saavedra Fajardo», en Víctor Mínguez (ed.), Del libro de emblemas a la ciudad simbólica. Actas del III Simposio Internacional de Emblemática Hispánica, Universidad Jaume I, Castellón, 2000, 2 volúmenes. Vol. II, págs. 621-646.
} 


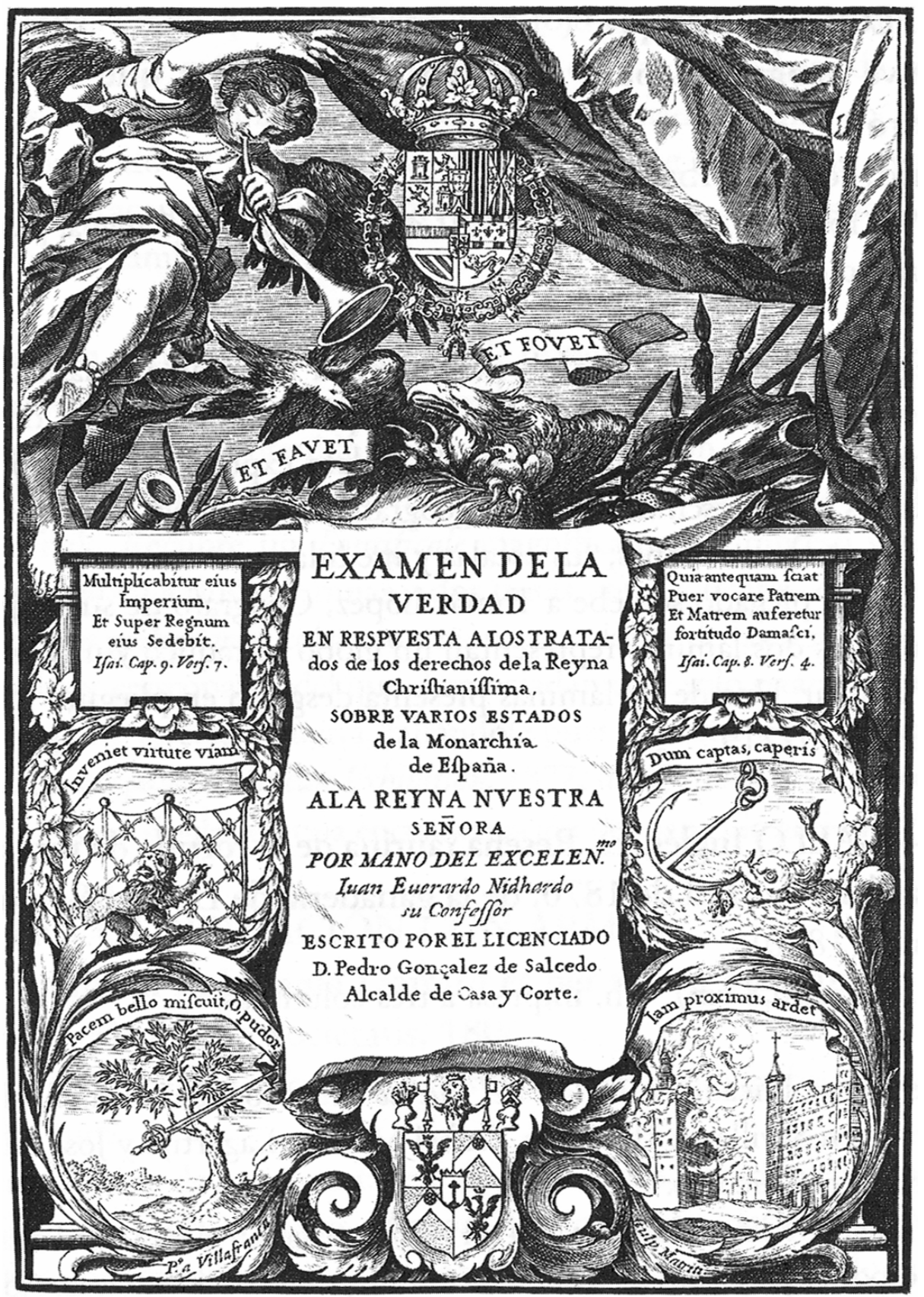

Figura 13

Además de la función de la portada como un emblema que transmite una información codificada al lector, la inclusión de emblemas múltiples en una 
sola portada puede verse en el siglo XVII con relativa frecuencia, como en la obra Examen de la verdad (1670), libro escrito por Pedro González de Salcedo en defensa de los intereses españoles en Flandes y de la reina regente española ${ }^{8}$ y dedicado a Juan Everardo Nithard, Consejero de Estado de 1666 a 1669 (figura 13). La portada, cuya estampa es de Pedro de Villafranca, el mejor grabador español del siglo XVII, presenta en la parte superior la figura de un ángel proclamando la verdad, y un águila madre - la reina regente, Mariana de Austria (el águila identificaba a los Austrias) - que acoge con su ala a un aguilucho que se dirige a ella (Carlos II, aún niño, por cuyos intereses vela). Junto al nido reposan aún las armas, que revelan la guerra que ha tenido lugar (Guerra de Devolución) ${ }^{9}$ que terminaría con la Paz de Aquisgrán, por la que España recuperaría la mayor parte de las plazas conquistadas por Luis XIV de Francia en Flandes y el Franco Condado). El lema dice "Et favet et fovet" (favorece y protege) en alusión a la función de reina regente que vela por los intereses del hijo que como niño aún no puede valerse por sí mismo. En la parte inferior, rodenado al título y bajo dos citas de Isaías, cuatro emblemas ayudan a comprender la situación: un león (Castilla, España) amenaza un parapeto o frontera establecido por Francia (representada por las flores de lis), un ancla de la que pende un toisón de oro se clava en las fauces de un delfín (Francia) avisando de que de atacante ha pasado a caer en la trampa. Los dos emblemas de abajo aluden a la guerra (espada) y la paz (olivo) y anuncian en qué terminará todo si no se logra esta última: el fuego devorará los más ricos palacios e iglesias. El conjunto anuncia el mensaje de la obra.

\section{Retratos emblemáticos}

Del mismo modo que las portadas, los retratos son una mezcla, por lo general, de motivos alegóricos y emblemáticos y texto; contenían mensajes muy bien estudiados por el sujeto representado y los artistas que lo llevaban a cabo. La costumbre data del siglo XVI, en que las empresas personales en ocasiones iban acompañadas de un epigrama que identificaba los ideales o motivos asociados a la persona que la poseía. Como un ejemplo, citaré una empresa del

\footnotetext{
${ }^{8}$ Examen de la verdad en respuesta à los tratados de los derechos de la Reyna christianissima sobre varios estados de la monarchia de España ... escrito por ... Pedro Gonçalez de Salcedo, Madrid, 1670.

${ }^{9}$ Luis XIV inició en mayo de 1667 la invasión de los Países Bajos alegando un principio de derecho privado, según el cual, a la muerte de uno de los cónyuges, la propiedad del superviviente pasaba a los hijos del primer matrimonio. Argumentando en ese sentido, a la muerte de Felipe IV de España (1665), el rey francés había reclamado sin éxito los Países Bajos en nombre de su esposa, María Teresa - la reina cristianísima a que alude el título - , que había renunciado al casarse con él (1660), a sus posibles derechos a la corona de España a cambio de una dote de 500.000 escudos de oro, pero que nunca fueron pagados.
} 
duque de Parma y Piacenza, Ottavio Farnese (1525-1586) realizada en aguafuerte firmado por BPV (de la escuela de Enea Vico) (figura 14). A la empresa le acompaña un epigrama en forma de soneto cuya finalidad es servir de explicación y complemento de la imagen. Alude al mito de Teseo, y se refiere al uso que hizo el héroe mitológico de tres armas en la prueba a que se sometió para vencer al minotauro: tres pelotas de brea, la maza y el hilo. Estas tres armas se utilizan como alegoría de la astucia, la fuerza y la prudencia, cualidades todas que se desean asociar a Ottavio Farnese, el duque de Parma y Piecenza.

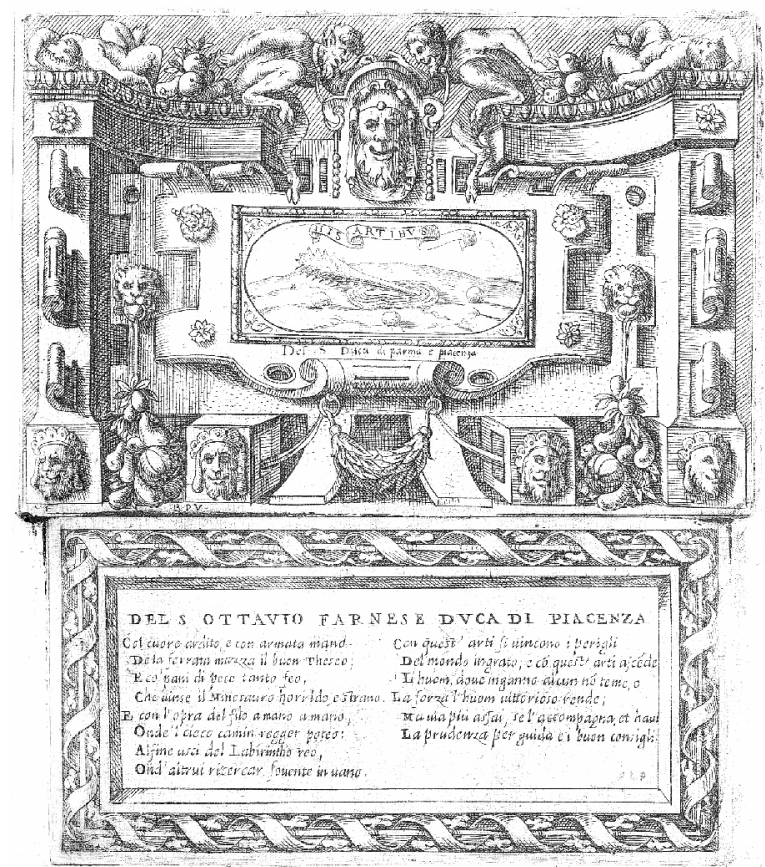

Figura 14

Paolo Giovio (1483-1552), obispo de Nocera e historiador reconocido puso de moda (recogiendo lo que estaba en el ambiente cortesano de la época) el retrato con asociaciones emblemáticas. Estuvo en estrecho contacto con los principales humanistas y fue un apasionado coleccionista de obras de arte, especialmente de retratos, que reunió en su casa, en Como, que él creía construida sobre el solar de la antigua villa de Plinio el joven y a la que denominó «Museo». Colocó debajo de cada retrato una inscripción, que luego publicó juntas como Elogia de las figuras históricas retratadas. 
Un conocido retrato emblemático es el del Conde-duque de Olivares, anterior a 1626, cuya ornamentación se debe a Rubens ${ }^{10}$ y que fue grabado en estampa calcográfica por Paulus Pontius (figura 15). El valido aparece con atributos de Minerva y Hércules que simbolizan la conjunción en su persona de sabiduría y valor, junto con el globo, el bastón y el timón, que aparecen sobre su figura para simbolizar su habilidad y prudencia política. Imagen y palabra de nuevo se unen en el grabado; en el epigrama de Gaspar Gevaert que aparece al pie, se alude a que el olivo triunfante (Olivares) extiende por todo el orbe sus pacíficas ramas.

A menudo estos retratos grabados figuraban al comienzo de obras literarias. Las muestras impresas de este tipo de retratos emblemáticos son más escasas en España que en otros países europeos. Faltaban editores promotores dispuestos a invertir, y pocos talleres podían arriesgar el enorme desenvolso - sujeto por otra parte a un éxito incierto- para pagar a dibujantes, maestros capaces de abrir las planchas, grabadores... Las leyes restrictivas para la imprenta desde la

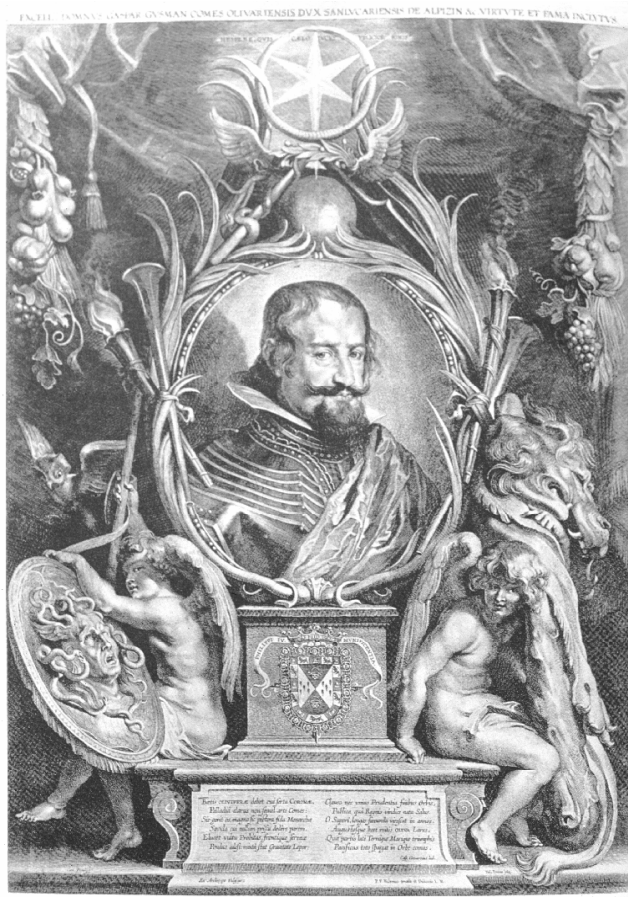

Figura 15 segunda mitad del siglo XVI y los precios elevados del papel y otros materiales, unido todo ello al miedo a la intervención de la Inquisición que podía mandar eliminar un material ya terminado, animaban a pocos a este tipo de empresas.

Aun así, algunos autores se hicieron retratos emblemáticos, encargaron los grabados y los insertaron al comienzo de sus obras, como el que acompaña a la segunda edición de Quevedo de Epicteto y Phocílides (Madrid, 1635), que

10 Rubens se inspira en un retrato del conde-duque de Velázquez. El dibujo de Rubens se conserva en los Musées Royaux del Beaux-Arts de Belgique. 
encargó a Juan de Noort ${ }^{11}$ y en el que, a imitación de Lipsio, pretende transmitir su filiación neoestoica.

\section{Pasquines y otro material de imprenta emblemático}

De igual modo, los emblemas tuvieron influencia en los pasquines políticos de carácter satírico tan empleados para la propaganda en momentos de crisis con países en conflicto. Ambrogio Spínola, que invadió el Palatinado en 1620 hizo buen empleo de la caricatura política empleando códigos emblemáticos. Se reimprimieron los Emblematum ethico-politicorum centuria (Heidelberg, 1619) del partisano palatino Julius Wilhelm Zincgreff y, donde el original mostraba, por ejemplo, la tela de una araña para representar al monarca prudente (emblema XXV: Non laetata diu spes probata el nuevo emblema caricaturesco muestra al Elector Palatino como un león destrozado por una tela de araña (la estrategia de Spínola).

Con mucha más frecuencia se editaban cartelones con imágenes satíricas acompañadas de poco texto que ridiculizaban al enemigo. Las guerras y tensiones de España con Países Bajos produjeron un interesante material en este sentido destinado al vituperio político y moral, la denuncia y el escarnio. Naturalmente, los peligros a que se exponía el emisor de semejantes obras (que por lo general incurría en delitos contra el Estado o la Religión, o en materias en que intervenía la Inquisición) ha hecho que, o bien nunca llegaran a la imprenta, o si lo hacían, solía ser fuera de España, en países de larga tradición de grabadores y con talleres de imprenta capacitados. Estos requisitos se daban en muchas ciudades de los Países Bajos y de las provincias Flamencas bajo el dominio español, que vivían su situación política como una ignominia. Por ello, algunos artistas (a menudo por encargo) realizaban emblemas con todos sus componentes (mote, pictura y epigrama) empleando los mejores recursos satíricos para denunciar y afrentar al opresor y los imprimían en estampas que llegaban a los círculos «avisados» donde sin duda suscitaban gran regocijo.

11 Ver trabajo de Henry Ettinghausen: "Neostoicism in Pictures: Lipsius and the Engraved Titlepage and Portrait in Quevedo's Epicteto y Phocilides", Modern Language Review 66 (1971), pp. 94100. 


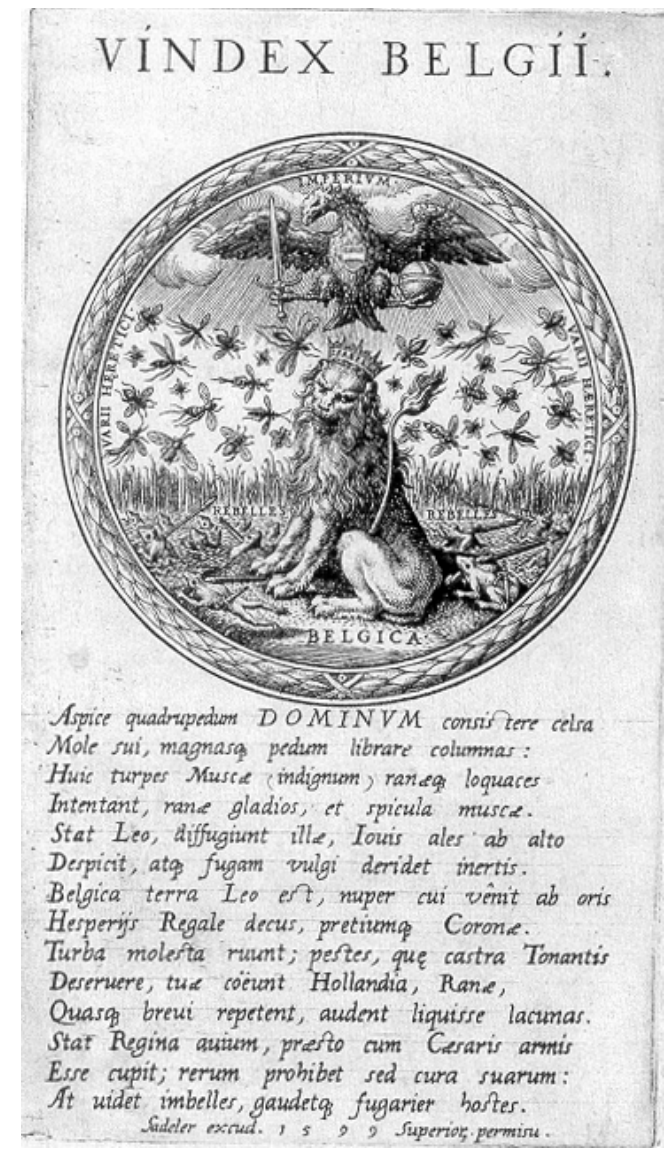

Figura 16

En muchas de esas composiciones se emplean metáforas animalísticas que llegaron a ser lugares comunes, como en la estampa calcográfica de Johannes Sadeler I, de 1599 (figura 16) ${ }^{12}$ que hace referencia al león coronado, Bélgica, (Isabel Clara Eugenia) y al águila española reinante (Imperium) que sostiene en sus garras una espada y un globo terráqueo. Las moscas y mosquitos (varii haeretici) revolotean como herejes alrededor de la cabeza del león; a su lado, las ranas (rebelles) huyen. Debajo del círculo aparece un epigrama de catorce versos que explican la imagen, por la que se alude a la nueva soberana de los Países Bajos meridionales (Isabel Clara Eugenia) y expresa un lamento dirigido a los reyes Felipe II y Felipe III que han descuidado (financieramente) a los Países Bajos. Simboliza los acontecimientos políticos de los años anteriores y las tensas relaciones con las Provincias Unidas.

12 Estampa calcográfica de Johannes Sadeler I (1599). Bruselas, Bibliothèque Royale Albert Ier, cabinet des Estampes S IV 235494. 
En otro ejemplo (figura 17) ${ }^{13}$ vemos que los españoles están metamorfoseados en cerdos que han irrumpido en un corral que no es suyo, y el león de Bélgica (se denominaba así porque sus provincias en el mapa representaban la figura de un león) les expulsa.

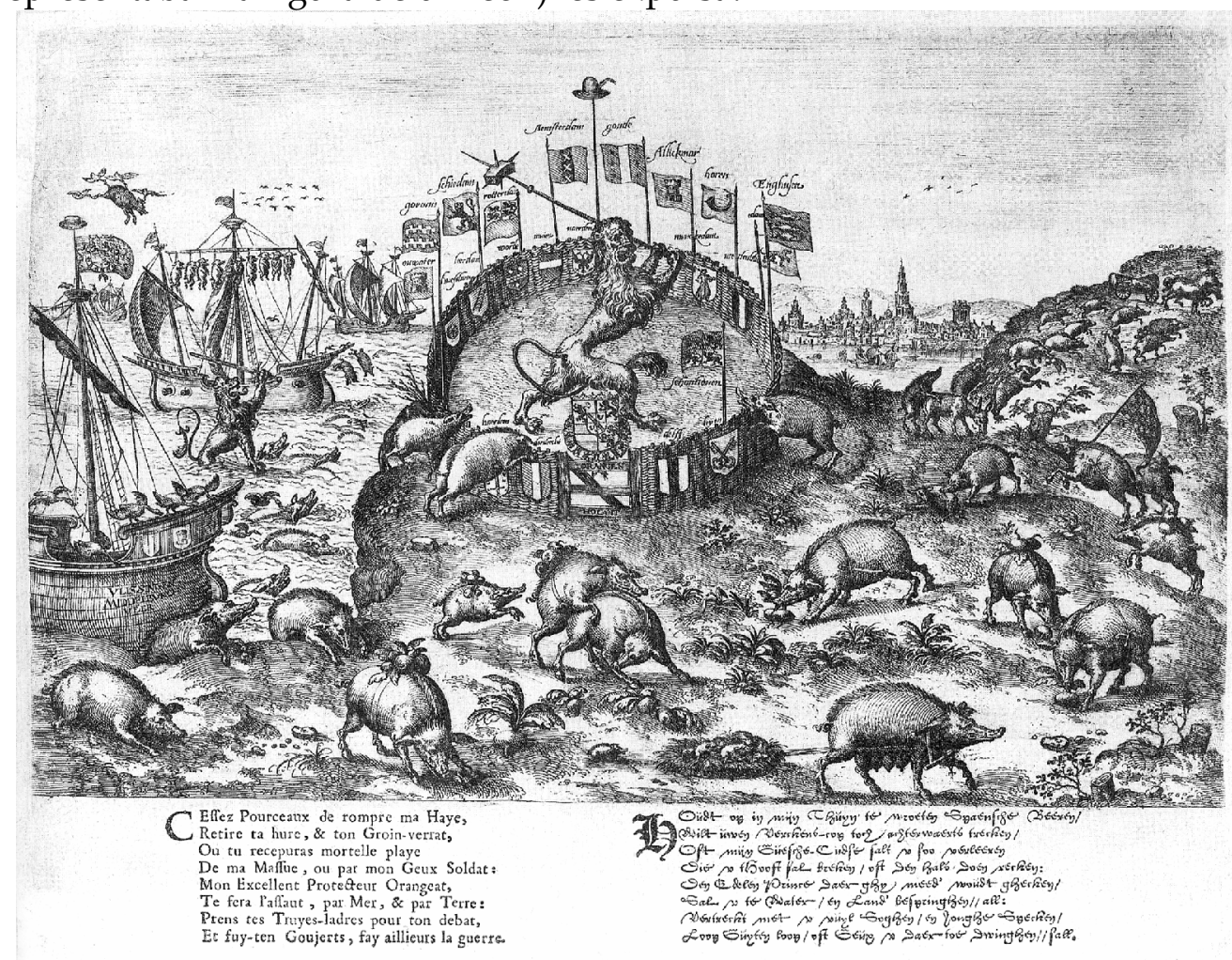

Figura 17

Vemos pues que la cultura emblemática y la imprenta tuvieron una estrecha relación, aunque no exenta de dificultades. Los códigos asociados a las empresas, que habían sido transmitidos durante largo tiempo de forma oral, y luego mediante la literatura en diálogos humanísiticos, pronto se concretaron en formas fijas gracias a grabados que se transmitieron a través de la imprenta (bien como libros de emblemas propiamente dichos, como relaciones festivas que recogían los jeroglíficos expuestos en la fiesta efímera, las divisas

13 Grabado anónimo en torno a 1572. Apud: James Tanis \& Daniel Horst, Images of Discord. A Graphic Interpretation of the Opening Decades of the Eighty Year's War, Bryn Mawr (PA), Bryn Mawr College Library, 1993, pág. 35. 
Los libros de emblemas y la imprenta

caballerescas, los pasquines de vituperio político, las portadas y retratos alegóricos...) Los impresores, libreros y promotores de esas obras sintieron una pasión por la emblemática que plasmaron a su vez en sus divisas personales y que perduraría más tarde en los exlibris de muchos aficionados a esa cultura simbólica. Aún nos queda mucho por estudiar de esta interesante relación, de la que esto que presento no es más que un apunte.

\section{PIES DE LAS ILUSTRACIONES}

\section{Ilustraciones}

Figura 1: Sebastián de Covarrubias, Emblemas morales, 31.

Figura 2: Joannes Sambucus, Emblemata.

Figura 3: Marca de impresor de Aldo Manucio.

Figura 4: Moneda de Tito Vespasiano.

Figura 5: «Semper festina tarde» - Hypnerotomachia Poliphili.

Figura 6: Gabriele Simeoni, Imprese heroiche et morali.

Figura 7: Marca de Barthélemy Honoré

Figura 8: Marca del impresor Bartolomeo Sermartelli.

Figura 9: Marca de impresor de Plantin.

Figura 10: Marca de Giolito

Figura 11: Marca de Marcolini

Figura 12: Portada obras completas de Justo Lipsio, 1637.

Figura 13: Portada de Examen de la verdad (1670).

Figura 14: Empresa de Ottavio Farnese (1525-1586).

Figura 15: Retrato del Conde-duque de Olivares (Rubens-Pontius).

Figura 16: Estampa calcográfica de Johannes Sadeler I (1599).

Figura 17: Grabado anónimo en torno a 1572. 